ORIGINAL ARTICLE

AFRICAN JOURNAL OF CLINICAL AND EXPERIMENTAL MICROBIOLOGY

SEPTMBER 2010

ISBN 1595-689X VOL 11(3)

AJCEM/200972/21017

-http://www.ajol.info/journals/ajcem

COPYRIGHT 2010

AFR. J. CLN. EXPER. MICROBIOL 11(3): 138-145

\title{
MOLECULAR IDENTIFICATION AND PREVALENCE OF MYCOBACTERIUM TUBERCULOSIS COMPLEX AMONGST PEOPLE LIVING WITH HIV IN OSUN STATE, NIGERIA.
}

\author{
${ }^{1}$ O.A. Terry Alli, ${ }^{1}$ Ogbolu, D.O., ${ }^{1}$ Salawu, M.A., ${ }^{2}$ Oyedeji, J.G., ${ }^{3}$ Oladokun, L., and ${ }^{3}$ Obaseki, F
}

${ }^{1}$ Departments of Biomedical Sciences, and ${ }^{2}$ Department of Medical Microbiology and Parasitology,College of Health Sciences, Ladoke Akintola University of Technology, Osogbo, Nigeria; ${ }^{3}$ State Hospital, Asubiaro, Osogbo, Nigeria; and ${ }^{4}$ Department of Medical Microbiology and Parasitology, University College Hospital, Ibadan.

Runnning title: Molecular identification of Mycobacterium tuberculosis complex in people living with HIV

Correespondence: Dr O.A.Terry Alli (alliot@hotmail.com)

\begin{abstract}
Human immunodeficiency virus (HIV) infection has created a special niche for Mycobacterium tuberculosis complex in humans as a result of the defect/reduction in cell mediated immunity. M. tuberculosis still responsible for most cases of death due to infectious diseases after HIV. In this study, prevalence of M. tuberculosis was determined in people living with HIV in Osun state of Nigeria with identification of culture positive isolates by polymerase chain reaction. A total of 160 samples were collected from people living with HIV with mean age of 36.8 years old of age (Median -34; age range 16 - 68; $95 \%$ confidence interval - 2.49) after seeking ethical approval from the Ministry of Health, Osun State. The result of the microscopy by ZN stain showed that $40(25 \%)$ of the 160 samples were positive for acid fast bacilli while culture on Lowenstein-Jensen (LJ) medium revealed that $30(18.75 \%)$ of the samples processed, grew organism that conformed to the characteristics of $M$. tuberculosis complex. Polymerase chain reaction for IS6110 was used to confirm the identity of the colonies on LJ slope as M. tuberculosis complex while the PCR for $260 \mathrm{bp}$ of Rv1255c was used in identifying M. tuberculosis. M. tuberculosis represented $92 \%$ of the M. tuberculosis complex. The prevalence of $M$. tuberculosis among people living with HIV was found to be $15 \%$ after PCR identification. The effects of socio-demographic factors on the prevalence of TB were analysed. Occupation was found to be associated with the proportional distribution of TB in people living with HIV $\left(X^{2}=14.85 ; p<0.05\right)$. The study concluded that PCR should be integrated into the schema for identification of tuberculosis in reference laboratories in developing countries.

Key words: Molecular identification, Polymerase chain reaction, Mycobacterium tuberculosis complex; Mycobacterium tuberculosis, Prevalence, HIV, Nigeria
\end{abstract}

\section{Introduction}

Tuberculosis (TB) is responsible for most cases of illness and death worldwide, especially in Asia and Africa. Worldwide, 9.2 million new cases and 1.7 million deaths from TB occurred in 2006, of which 0.7 million cases and 0.2 million deaths were reported in human immunodeficiency virus (HIV) positive people (1). The problem of TB has been compounded by the emergence of multi-drug resistance Mycobacterium tuberculosis and HIV.

The aetiological agent of $\mathrm{TB}$ is $M$. tuberculosis complex. M. tuberculosis complex is a Gram positive rod which can be best described by the ability to hold on to stain such as carbol fuschin even after decolourization with acid alcohol as acid fast bacilli. M. tuberculosis complex so called because of the similarity in pathology of the infection comprises $M$. tuberculosis, $M$. bovis including Bacille Calmette Guerin (BCG) strain, M. canetti, M. africanum, and $M$. microti. Causative agent of $\mathrm{TB}$ is a facultative intracellular organism. The pathogenesis starts with the invasion of alveoli macrophages after inhalation of the contaminated droplets by individuals. The organism able to resist macrophage killing by inhibiting phagosomal-lysosome fusion (2-4) and the detail mechanisms have been described by various researchers (2-7). The initial involvement with macrophages involved the use of receptors (complement receptors, mannose receptor, and type A scavenger receptors) present on the macrophage (810). Ability to adapt to the intracellular niche has played important role in the organism. One of the important mechanisms is for the organism to shift majority of its metabolism to fatty acid metabolism (11) and also ability to enter into state of dormancy have played important roles in the parasitism of the host. State of dormancy has been characterized by the increase in expression of a-crystallin protein (12). It has been reported that a-crystallin protein expression increases with anoxic condition (13) and it also increases during intracellular gene expression (14) with other key metabolites. Several workers in the field of mycobacteriology have used different molecular biological techniques such as transposon 
mutagenesis (15), microarray (16), RAP-PCR (17) to mention a few, in unraveling the intracellular survival strategy of M. tuberculosis.

Epidemiologically, African countries have not been faring well since late 1980s and this has coincided with the HIV pandemic. Co-infection of people living with HIV with $M$. tuberculosis has been shown to increase the mortality rate in sub-Saharan African countries like South Africa, Botswana, and Zambia (18). Nigeria was ranked fifth as high burden country with tuberculosis according to World Health Organization (WHO) report of 2008 (1). According to this report, there were 311 cases of TB per 100,000 population per year. Six hundred and ninety four laboratories performing microscopy for AFB with none of them routinely culturing for mycobacteria and 6 states out of 30 states in Nigeria were mentioned as those involved in TB/HIV collaborative activities. Osun state was not one of the states mentioned in WHO report, suggesting that there is dearth of information on the TB/HIV epidemiology in Osun state. The information on the epidemiology of TB in people living with HIV has been sketchy or not well documented in this part of Nigeria (Osun state) because there is no laboratory facility to do both microscopy and culturing of samples for isolation and identification of mycobacteria routinely. Furthermore, rapid identification of $M$. tuberculosis complex from culture can provide better alternative to identification than the biochemical tests normally employed at reference laboratories. Therefore, the study was aimed at determining the prevalence of $M$. tuberculosis among people living with HIV in Osun State, Nigeria using cultural and molecular methods for identification of M. tuberculosis.

\section{Materials and Methods}

\section{Sample Population and Selection.}

The target population for this study was people that had been confirmed to be infected with HIV by serological diagnosis to be reactive or positive for Human immunodeficiency virus I/II residing in Osun state of Nigeria. Ethical approval was obtained from the Ministry of Health, Osun state, Nigeria before the commencement of the study. Standard questionnaire was provided in order to collect biodata and informed consent was obtained from the patient prior to collection of sputum

sample(s). Samples were collected from the people living with HIV between March and July, 2008.

\section{Sample Collection.}

The samples were collected from seven locations in Osun state: Ilesa, Osogbo, Telemu, Ogbagba, Iwo, Ikire, and Ejigbo in Osun State, Nigeria. Samples were collected randomly from people living with HIV/AIDS in those cities/towns aforementioned. Three sputum specimens were collected in wide mouthed translucent containers (cups). Sputum produced from a deep cough into one of the container on the first day. The subjects took the second sputum cup home and produced early morning sputum from a deep cough. On arrival with the early morning specimen, another sputum specimen (second spot specimen) was collected from each subject. The samples were taken to the laboratory for microbiological analysis.

\section{Mycobacteriology}

Processing of Samples

All the sputum samples and cultures were processed in the TB laboratory, Department of Medical Microbiology, University College Hospital, Ibadan, Nigeria inside a safety cabinet as described below.

Microscopy.

A loopful of sputum was spread on a clean glass slide uniformly in oval shape by smearing repeatedly in coil-like patterns, approximately $2-3 \mathrm{~cm}$ in size. After smearing, the slide was air dried completely. Then, flame-fixed by passing through the flame carefully so that it would not wash off during staining. The smear was stained for presence of acid fast bacilli using Ziehl-Nelseen staining as described previously (19) and examined under light microscope using the oil objective.

\section{Cultural Isolation of Mycobacteria.}

Sputum specimens were processed for culture by first decontaminating/digestion. Briefly, $10 \mathrm{ml}$ of $4 \%$ $\mathrm{NaOH}$ was added to about $5 \mathrm{ml}$ or equivalent proportion, the cap of the container was tightened and shook to digest. It was allowed to stand for 15 min at room temperature with occasional shaking and centrifuged at $2000 \times \mathrm{g}$ for $10 \mathrm{~min}$, after which the supernatant was poured off into a stericol disinfectant jar. The deposit was re-suspended in sterile saline and centrifuged at $2000 \times \mathrm{g}$ for $15 \mathrm{~min}$. The resultant deposit was inoculated onto Lowenstein-Jensen (LJ) medium. The culture was incubated at $35-37^{\circ} \mathrm{C}$ until growth was observed for maximum period of 8 weeks. All cultures were compared with the control organism (H37Rv). Every week after the inoculation, LJ slopes were removed from incubator and observed for 4 characteristics: aspect/consistency of the culture media; growth rate of the colonies; morphology of the colonies; and colour of the colonies (presence of pigmentation).

\section{Bioinformatics and Primers design}

In order to help in identification of M. tuberculosis and $M$. tuberculosis complex, the whole genomes sequences of $M$. tuberculosis (H37Rv) (20) and M. bovis (21) were downloaded from the www.sanger.ac.uk. ARTEMIS software designed to view microbial genome was used to view the genomes sequences of both organisms. Artemis comparison tool (22) was used to identify a region that was unique to $M$. tuberculosis that was not present in $M$. bovis. Primers were designed for amplification of the unique region using DNAman. The primers were designed for specificity by submitting the primers sequences to 
BLAST programme at National Centre for Biotechnology and information website (www.ncbi.nih.gov/blast).

\section{DNA Extraction}

DNA was extracted from the representative colonies suspected to grow organism irrespective of whether the culture resembled $M$. tuberculosis complex culture as described before (23). Briefly, the LJ slope containing suspected colonies was heated at $80^{\circ} \mathrm{C}$ for $1 \mathrm{~h}$ to kill bacteria. Thereafter $3 \mathrm{ml}$ of extraction buffer (50 mM Tris- $\mathrm{HCl}, 25 \mathrm{mM}$ EDTA, 5\% mono-sodium glutamate, $\mathrm{pH}$ 7.4) was added and the colonies were carefully scraped using a disposable loop and homogenised using a vortexer for 2-3 min to disrupt colonies. Four hundred microlitre of $50 \mathrm{mg} / \mathrm{ml}$ lysozyme stock and $10 \mu \mathrm{l}$ of $10 \mathrm{mg} / \mathrm{ml}$ RNAase were added to the suspension and incubated at $37^{\circ} \mathrm{C}$ for 2 h. Subsequently, $600 \mu \mathrm{l}$ of $10 \mathrm{X}$ proteinase $\mathrm{K}$ buffer (100mM Tris- $\mathrm{HCl}, 50 \mathrm{mM}$ EDTA, 5\% SDS, pH 7.8) was added with $150 \mu \mathrm{l}$ of $10 \mathrm{mg} / \mathrm{ml}$ proteinase $\mathrm{K}$ and incubated at $45^{\circ} \mathrm{C}$ for $16 \mathrm{~h}$. The DNA was purified using phenol/chloroform/isoamyl alcohol and precipitated from upper aqeous phase using equal volume of isopropanol in the presence of 0.1 volume of $3 \mathrm{M}$ sodium acetate, $\mathrm{pH} 5.5$ at $-20^{\circ} \mathrm{C}$ for $30 \mathrm{~min}$. The resulting DNA pellet after centrifugation at $3000 \times \mathrm{g}$ for $30 \mathrm{~min}$ was suspended in TE buffer $(10 \mathrm{mM}$ Tris$\mathrm{HCl}, 1 \mathrm{mM}$ EDTA, $\mathrm{pH} 8.0)$ and stored at $-20^{\circ} \mathrm{C}$.

Polymerase Chain Reaction (PCR)

After the DNA extraction, about $50 \mathrm{ng}$ of the DNA sample was added to the PCR master mix prepared in the presence of Taq polymerase and IS6110F (cctgcgagcgtaggcgtcgg) and IS6110B (ctcgtccagcgccgcttcgg) primers to amplify $123 \mathrm{bp}$ insertion sequence element present in all $M$. tuberculosis complex. The reaction mixture was made up of $1.5 \mathrm{mM} \mathrm{MgCl}_{2}, 0.2 \mathrm{mM} \mathrm{dNTP}, 50 \mathrm{mM} \mathrm{KCl}, 5 \%$ glycerol, $1 \mathrm{uM}$ of IS6110F, $1 \mathrm{uM}$ of IS6110B and 25 units of Taq polymerase (New England Biolab, USA) in a 20 ul reaction volume. The following cycling parameters were used for amplification of $123 \mathrm{bp}$ IS6110 fragment in positive $M$. tuberculosis complex cultures: $94^{\circ} \mathrm{C}$ for $5 \mathrm{~min} ; 94^{\circ} \mathrm{C}$ for $1 \mathrm{~min}, 68^{\circ} \mathrm{C}$ for 1 $\min , 72^{\circ} \mathrm{C}$ for $2 \mathrm{~min}-25$ cycles; $72^{\circ} \mathrm{C}$ for $7 \mathrm{~min}-1$ cycle. The amplicons were run along with DNA size markers on $0.7 \%$ agarose gel with positive control (DNA from H37Rv) and negative control (no DNA). The specific M. tuberculosis DNA was amplified using the primers stb_F1 (accgagttagcccgcaga) and stb_B1 (cgtcgtggtgatgctca) using the procedure above with different cycling parameters from above to amplify $260 \mathrm{bp}$ : $94^{\circ} \mathrm{C}$ for $2 \mathrm{~min} 1 \mathrm{cycle}, 94^{\circ} \mathrm{C}$ for $5 \mathrm{~min} ; 94^{\circ} \mathrm{C}$ for $1 \mathrm{~min}, 55^{\circ} \mathrm{C}$ for $1 \mathrm{~min}, 72^{\circ} \mathrm{C}$ for $30 \mathrm{sec}-25$ cycles; $72^{\circ} \mathrm{C}$ for $7 \mathrm{~min}-1$ cycle.

\section{Statistical Analysis}

Data were analysed using statistical package within the Microsoft Excel and Epi-info software from Centre for Disease control and prevention, USA. Chi square was used to determine the effect of sex, age, location, and occupation on the data obtained. The $p$ value less than 0.05 was considered to be significant.

\section{RESULTS}

In this study, 160 sputum samples were obtained randomly from people living with HIV/AIDS in Osun State of Nigeria of average age of 36.8 years old (Median -34; age range $16-68 ; 95 \%$ confidence interval - 2.49). The result of the microscopy by $\mathrm{ZN}$ stain showed that $40(25 \%)$ of the 160 samples were positive for acid fast bacilli (AFB) while 42 (26.3\%) were positive for culture (see Fig.1). Four of the 120 samples negative by microscopy grew organism suspected to be $M$. tuberculosis complex.

There was no significant difference in the level of detection of mycobacteria between microscopy and culture on LJ $\left(X^{2}=0.02 ; p>0.05\right)$. Most of the growths were noticed 4 weeks after incubation. Using culture as the gold standard, sensitivity and specificity for microscopy were found to be $73 \%$ and $100 \%$, respectively.

Primers for amplification of the insertion sequence

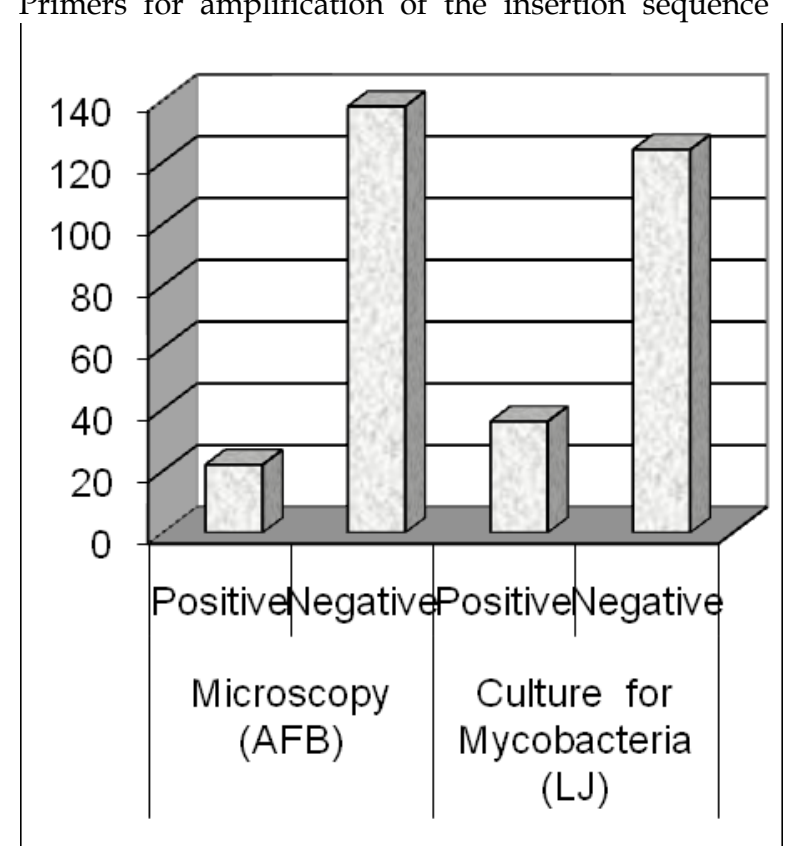

Fig.1. Comparison of number of cases positive by microscopy and culture in diagnosis of tuberculosis. Microscopy was carried out on all the specimens by staining smear of sample using ZN staining technique while culture was done on $L J$ slope as described in the materials and methods. 
element of $M$. tuberculosis complex had been used before by various researchers (24-26) and therefore no need for analysis of the primers for suitability. The primers designed specifically to amplify $M$. tuberculosis were designed based on the comparison of the genomes sequences of $M$. tuberculosis and $M$. bovis.

Various regions of the genome were identified to be unique to M. tuberculosis: Rv1255c-R1257c, Rv1369c, Rv1506c, Rv1507c - Rv1516c, Rv1976c, Rv2073c, Rv2106c, to mention few of such regions. One (Rv1255c) of such regions was selected and primers were designed using the primer design programme within DNAman. The primers were submitted for BLAST at ncbi website to make sure that the primers would not amplify any region of the DNA from other organisms including human DNA. Using the IS6110F and IS6110B, all DNA extracted from culture positive samples irrespective of the colonial appearance were subjected to PCR to identify M. tuberculosis complex. The result of the PCR for $M$. tuberculosis complex showed that $30(18.75 \%)$ of the 160 samples cultured were positive for PCR for $M$. tuberculosis complex representing $75 \%$ of the suspected culture positives. Twenty four $(80 \%)$ of the $30 \mathrm{M}$. tuberculosis complex isolates were positive for PCR that was designed to identify $M$. tuberculosis alone. Representative of the PCR for M. tuberculosis complex and M. tuberculosis are shown on Figures 2 and 3, respectively.

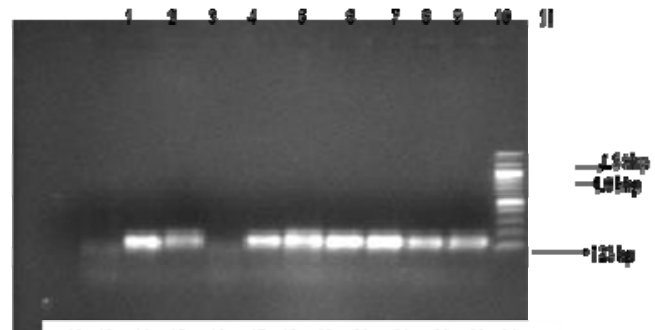

$\begin{array}{lllllllllllll}12 & 13 & 14 & 15 & 16 & 17 & 18 & 19 & 20 & 21 & 22 & 23 & 24\end{array}$

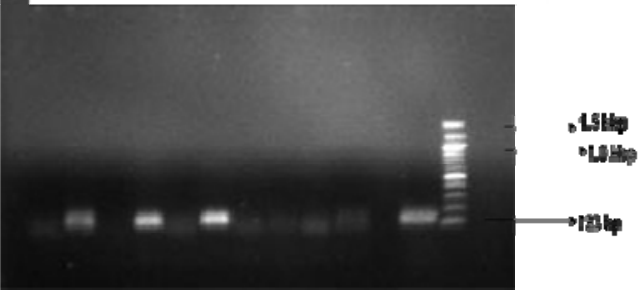

Fig.2. PCR for Mycobacterium tuberculosis complex. Agarose gel electrophoresis of representative samples. Lanes 1-10 and 12-21: PCR of various cultures from LJ slopes; lane 22: negative PCR control; lane 23: PCR positive control (H37Rv DNA); and lanes 11 and 24: 100 bp DNA ladder molecular weight size marker. Positive PCR product is indicated by arrow showing $123 \mathrm{bp}$.

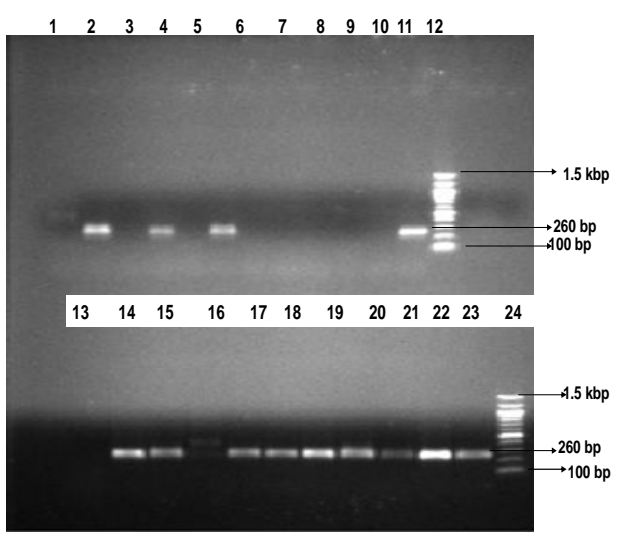

Fig. 3. PCR for Mycobacterium tuberculosis Agarose gel electrophoresis of representative samples. Lanes 1-8 and 12-21: PCR of various cultures from LJ slopes; lane 9: negative PCR control; lane 10: PCR positive control (H37Rv DNA); and lanes 12 and 24: $100 \mathrm{bp}$ DNA ladder molecular weight size marker. Positive PCR product is indicated by arrow showing $260 \mathrm{bp}$.

Table 1 shows the proportional distribution of $M$. tuberculosis complex among people living with HIV according to sex. There was no significant difference between the prevalence of $M$. tuberculosis complex in male $(21.1 \%)$ and female $(18 \%)\left(X^{2}=0.17 ; p>0.05\right)$ in people living with HIV.

Table 1. Proportional Distribution of M. tuberculosis complex among people living with HIV

\begin{tabular}{lccc} 
& $\begin{array}{c}\text { Positive for } \\
M . \\
\text { tuberculosis } \\
\text { complex }\end{array}$ & $\begin{array}{c}\text { Negative for } \\
\text { Sex } \\
\text { tuberculosis } \\
\text { complex }\end{array}$ & Total \\
\hline Male & $8(26.67)$ & $30(78.95)$ & 38 \\
Female & $22(18.00)$ & $100(82.00)$ & 122 \\
Total & $30(18.75)$ & $130(81.25)$ & 160 \\
\hline
\end{tabular}

Number in parenthesis - percentage

Chi square $=0.17, \mathrm{P}=0.89$

Furthermore, there was no significant difference between prevalence of $M$. tuberculosis in male $(21.1 \%)$ and female $(13.1 \%)\left(X^{2}=0.88 ; p>0.05\right)$. $)$. The prevalence of $M$. tuberculosis complex among people living with HIV was found to be $18.75 \%$. There was increase in proportional distribution of $M$. tuberculosis complex with increasing age (Fig. 4). The only age group that did not follow this trend was 21-30 age group which recorded $25 \%$ in proportional distribution. With this trend, 61-70 age group recorded the highest proportional distribution (33.3\%) while 11-20 recorded the lowest proportional 
distribution $(0 \%)$. There was no association between age and proportional distribution of tuberculosis in people living with $\mathrm{HIV}\left(\mathrm{X}^{2}=7.16 ; \mathrm{p}>0.05\right)$. Removing the age group 21 to 30 from statistical analysis showed that there was linear association between age and tuberculosis in people living with HIV $\left(X^{2}=4.278 ; \mathrm{P}<0.05\right)$. Fig. 5 shows the occupational distribution of $M$. tuberculosis complex among people living with HIV.

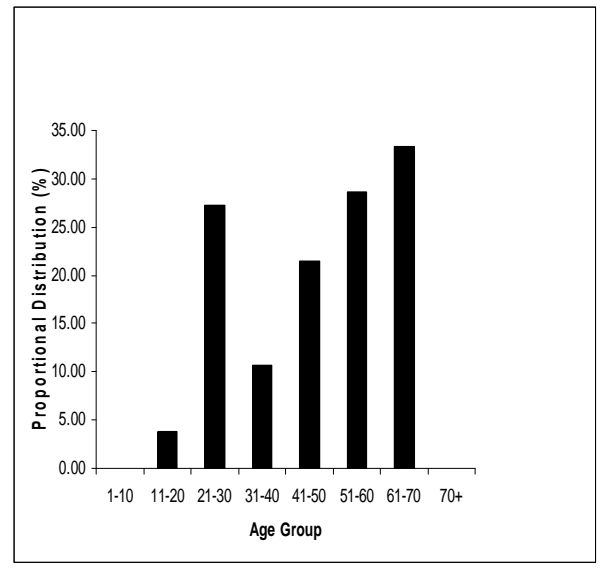

Fig. 4. Age distribution of M. tuberculosis complex among people living with HIV.

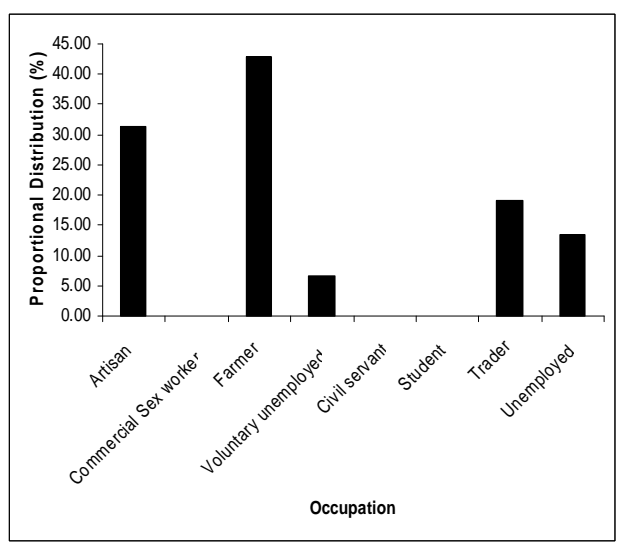

Fig. 5: Occupational distribution of M.tuberculosis complex among people living with HIV.

Highest proportional distribution of tuberculosis was recorded among farmers $(42.9 \%)$, followed by artisans $(31.3 \%)$, and lowest among students $(0 \%)$ and commercial sex workers $(0 \%)$. There was association of occupation with proportional distribution of tuberculosis in people living with $\operatorname{HIV}\left(X^{2}=14.85 ; \mathrm{p}<\right.$ 0.05). Figure 6 shows the distribution of $M$. tuberculosis among people living with HIV in Osun state with respect to the residential location. Ikirun recorded the highest proportional distribution
$(37.5 \%)$, followed by Ilesa $(28.6 \%)$ with lowest proportional distribution $(0 \%)$ recorded for Telemu. Association was not found between residential location and prevalence of tuberculosis $\left(X^{2}=9.40 ; p>\right.$ 0.05).

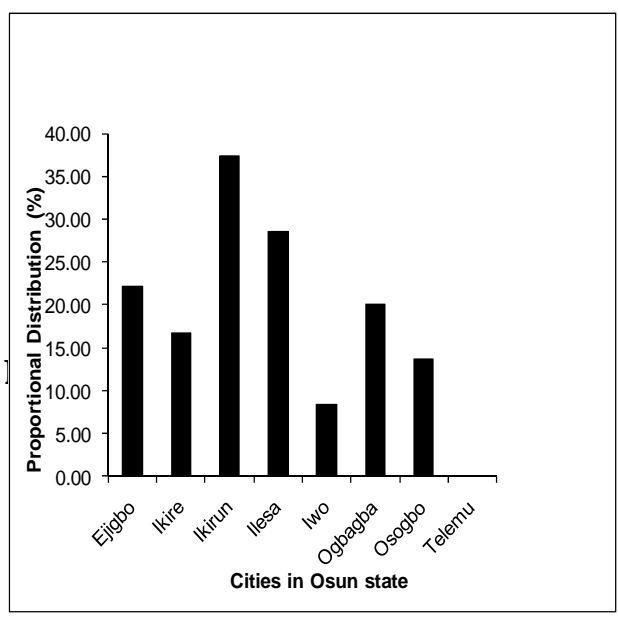

Fig. 6. Distribution of $M$. tuberculosis complex among people living with HIV according to their residential location.

M. tuberculosis is the leading cause of death after HIV from infectious diseases $(1,18)$. The combination of HIV and $M$. tuberculosis infection increases the mortality rate due to infectious disease. In order to curb the menace due to $M$. tuberculosis there is need for speedy, accurate laboratory diagnosis which will eventually lead to adequate treatment. This study was designed to highlight the scale of the problem facing policy makers in controlling this important infectious agent through adequate laboratory diagnosis. The prevalence of $M$. tuberculosis in people living with $\mathrm{HIV}$ in Osun state of Nigeria was found to be $25 \%$ using microscopy, and $15 \%$ and $18.75 \%$ for $M$. tuberculosis and M. tuberculosis complex, respectively, suggesting there is overestimation of TB cases using microscopy. This data is not in agreement with WHO report (2008) on the overall prevalence of TB among people living with HIV that was put at $9.5 \%$. A study carried out on patients attending out-patients clinic in Abeokuta, Nigeria estimated the prevalence of $M$. tuberculosis to be $14 \%$ (27) which is in agreement to $15 \%$ obtained in this study. Similarly, $16.7 \%$ prevalence of TB in people living with HIV/AIDS was reported in Keffi, Nigeria (28).

The overestimation of TB cases by microscopy in this study is not surprising because this method of laboratory diagnosis is not specific as there are other bacteria such as Nocardia spp and Actinomycetes spp 
and fungal elements that are acid fast. The most worrisome is that there is no method that is routinely used to differentiate $M$. tuberculosis complex from $M$. avium intracellulare complex in Nigeria because $M$. avium infection does not respond to usual anti-TB drugs. The delay in treating the infection with appropriate drugs can make a lot of difference between life and death. M. avium has been reported in people living with HIV (29). Culture which is a gold standard in laboratory diagnosis estimated the prevalence to be $26.3 \%$, this is without formal identification of the suspected colonies on LJ slope. Formal identification is very important for epidemiological purposes and also it can also give a clue to the way the infection should be treated if antiTB drug susceptibility testing is not carried out on the isolates. Drug susceptibility testing procedure for mycobacterial infection can only be best handled in reference laboratory. With the advent of several molecular biological techniques in the last 2 decades, this part can be handled with a laboratory that is well funded in developing countries.

In this study, PCR was carried out to identify the species of mycobacteria isolated in people living with HIV. The PCR was based on the IS6110 that was identified more than a decade ago in M. tuberculosis by Eisenach et al (24). This insertion sequence (IS6110) has been found in all $M$. tuberculosis complex in high copy number in majority of $M$ tuberculosis strains and 1 to 5 copies in $M$. bovis strains (30). The presence of IS6110 in high copy number makes it a good target for PCR because it enhances the sensitivity of detection of M. tuberculosis complex. Using IS6110 as target for PCR, $30(75 \%)$ of the 42 isolates were identified as $M$. tuberculosis complex while $24(63 \%)$ of the isolates were identified as $M$. tuberculosis, suggesting there are other species of mycobacteria infecting people living with HIV apart from $M$. tuberculosis within $M$. tuberculosis complex that has been erroneously reported. The prevalence of $M$. tuberculosis in people living with HIV after identification by PCR was estimated to be $15 \%$. A study carried out by Idigbe et al. using biochemical methods of identification (niacin production, nitrate reduction, catalase production, etc) found that not all mycobacteria isolated from patients with tuberculosis had M. tuberculosis, with $M$. bovis accounted for small proportion of the mycobacterial isolates (31). A detailed molecular epidemiological analysis of the isolates from Ibadan also showed that $M$. africanum and $M$. bovis accounted for $13 \%$ of the mycobacterial isolates (32). Various studies have reported the prevalence of tuberculosis among people living with HIV: Nwobu et al. (33) reported $10.8 \%$ and $9.2 \%$ in Irrua and Benin, respectively using Ziehl Neelsen staining. Idigbe et al. (34) reported $5.2 \%$ in Lagos while Onipede et al
(35) reported $12.9 \%$ in Ile-Ife (a town about $50 \mathrm{~km}$ away from this study site).

The limitation of our study was the inability of the methodology in identifying other species of mycobacteria apart from $M$. tuberculosis, suggesting the prevalence of other species of mycobacteria apart from $M$. tuberculosis cannot be determined with certainty. However, this study still gives an important clue to the most predominating mycobacteria infecting people living with HIV with accuracy and also demonstrates the usefulness of molecular biological technique in mycobacteria identification. It is possible to incorporate this methodology as part of the schema for laboratory diagnosis of tuberculosis.

The influence of different socio-demographic factors on the prevalence of $M$. tuberculosis complex on people living with HIV was examined. We found no association between gender and the prevalence of tuberculosis on the population studied $\left(X^{2}=0.02 ; p>\right.$ $0.05)$ with prevalence in males and females put at $21 \%$ and $18 \%$, respectively. This finding is in conformity with other studies $(27,28,33,36)$ that looked at the effect of gender on the prevalence of TB on people living with HIV. Pennap et al. (28) reported no significant difference in prevalence of $\mathrm{TB}$ in males $(19.4 \%)$ and females $(14.4 \%)$ co-infected with HIV in Keffi, in Nigeria, suggesting gender plays no role in prevalence of TB in people living with HIV. Although we found no significant association of age $(\mathrm{P}>0.05)$ with the prevalence of TB in people living with HIV, there was general increase in the prevalence of tuberculosis as the age progresses with the age group between 61 and 70 recording the highest proportional distribution. The plausible explanation for the highest proportional distribution recorded for 61-70 age group could be attributed to the weakening of the immune system (37). Even in the absence of HIV, this is the age group in general population where reactivation of latent tuberculosis takes place.

Moreover, we found association between tuberculosis and occupation; highest proportional distribution $(42.9 \%)$ was recorded among farmers living with HIV, followed by artisans. This study is not in agreement with the study carried out by Nwobu et al (33) where they found no association between occupation and tuberculosis in people living with HIV. The plausible explanation for this high prevalence among farmers can be attributed to physical nature of their job which could further weaken their immune system. The same reason can also be given for artisans. Mechanised farming is not adopted by large population of farmers in Nigeria, especially the area where this study was conducted. Animal husbandry especially cattle rearing and exposure to wild animals infected with $M$. bovis could probably expose farmers to 
tuberculosis. Our questionnaire did not address the kind of farming operation. Farming operations have been linked with infectious diseases like meliodosis (38) but this has not been proven for tuberculosis due to $M$. tuberculosis.

In conclusion, we have demonstrated the usefulness of PCR in laboratory diagnosis of tuberculosis. We recommend the integration of molecular techniques such as PCR in the final identification of $M$. tuberculosis complex / M. tuberculosis as this can provide timely intervention in the diagnosis of tuberculosis and treatment. Identification of suspected M. tuberculosis from culture is a prelude to studying the molecular epidemiology of this organism.

\section{Acknowledgements}

The molecular biology works were all carried out in the Molecular Biology Laboratory, Department of Biomedical Sciences, Ladoke Akintola University of Technology, Mercyland Campus, Osogbo. We would like to thank the Vice Chancellor (Professor B.B.A. Adeleke) and Management of Ladoke Akintola University of Technology for the establishment of the Molecular Biology Laboratory. We also acknowledge $\mathrm{Mr}$ Oyenike and Mr T. Raheem for their technical assistance.

\section{References}

1. WHO. Global Tuberculosis Control 2008: Surveillance, Planning, Financing. Geneva, Switzerland; 2008.

2. Brown CA, Draper P, Hart PD. Mycobacteria and lysosomes: a paradox. Nature 1969;221(5181):65860 .

3. Armstrong JA, Hart PD. Response of cultured macrophages to Mycobacterium tuberculosis, with observations on fusion of lysosomes with phagosomes. J Exp Med 1971;134(3 Pt 1):713-40.

4. Armstrong JA, Hart PD. Phagosomelysosome interactions in cultured macrophages infected with virulent tubercle bacilli. Reversal of the usual nonfusion pattern and observations on bacterial survival. J Exp Med 1975;142(1):1-16.

5. de Chastellier C, Thilo L. Modulation of phagosome processing as a key strategy for Mycobacterium avium survival within macrophages. Res Immunol 1998;149(7-8):699-702.

6. Russell DG, Dant J, Sturgill-Koszycki S. Mycobacterium avium- and Mycobacterium tuberculosis-containing vacuoles are dynamic, fusioncompetent vesicles that are accessible to glycosphingolipids from the host cell plasmalemma. J Immunol 1996;156(12):4764-73.

7. Sturgill-Koszycki S, Schaible UE, Russell DG. Mycobacterium-containing phagosomes are accessible to early endosomes and reflect a transitional state in normal phagosome biogenesis. Embo J 1996;15(24):6960-8.

8. Schlesinger LS, Bellinger-Kawahara CG, Payne NR, Horwitz MA. Phagocytosis of Mycobacterium tuberculosis is mediated by human monocyte complement receptors and complement component C3. J Immunol 1990;144(7):2771-80.

9. Schlesinger LS. Macrophage phagocytosis of virulent but not attenuated strains of Mycobacterium tuberculosis is mediated by mannose receptors in addition to complement receptors. J Immunol 1993;150(7):2920-30.

10. Hirsch CS, Ellner JJ, Russell DG, Rich EA. Complement receptor-mediated uptake and tumor necrosis factor-alpha-mediated growth inhibition of Mycobacterium tuberculosis by human alveolar macrophages. J Immunol 1994;152(2):743-53.

11. Alli OAT, Hingley-Wilson S, Ogbolu DO, Spreadbury CL. The Mycobacterium tuberculosis homologue of the Mycobacterium avium mig gene is not specifically expressed in the macrophage. African Journal of Biomedical Research 2008;11:173-181.

12. Yuan Y, Crane DD, Barry CE, 3rd. Stationary phase-associated protein expression in Mycobacterium tuberculosis: function of the mycobacterial alpha-crystallin homolog. J Bacteriol 1996;178(15):4484-92.

13. Cunningham AF, Spreadbury CL. Mycobacterial stationary phase induced by low oxygen tension: cell wall thickening and localization of the 16-kilodalton alpha-crystallin homolog. J Bacteriol 1998;180(4):801-8.

14. Yuan Y, Crane DD, Simpson RM, Zhu YQ, Hickey MJ, Sherman DR, et al. The 16-kDa alphacrystallin (Acr) protein of Mycobacterium tuberculosis is required for growth in macrophages. Proc Natl Acad Sci U S A 1998;95(16):9578-83.

15. McAdam RA, Weisbrod TR, Martin J, Scuderi JD, Brown AM, Cirillo JD, et al. In vivo growth characteristics of leucine and methionine auxotrophic mutants of Mycobacterium bovis BCG generated by transposon mutagenesis. Infect Immun 1995;63(3):1004-12.

16. Schnappinger D, Ehrt S, Voskuil MI, Liu Y, Mangan JA, Monahan IM, et al. Transcriptional Adaptation of Mycobacterium tuberculosis within Macrophages: Insights into the Phagosomal Environment. J Exp Med 2003;198(5):693-704.

17. Alli OAT, Butcher PD, Mangan JA, Akinloye $\mathrm{O}$, Spreadbury CL. The use of RAP-PCR to study intracellular gene expression of Mycobacterium tuberculosis. African Journal of Clinical and Experimental Microbiology 2009;10(3):185-199.

18. Corbett EL, Watt CJ, Walker N, Maher D, Williams BG, Raviglione $\mathrm{MC}$, et al. The growing burden of tuberculosis: global trends and interactions 
with the HIV epidemic. Arch Intern Med 2003;163(9):1009-21.

19. Alli OAT. Development of a RAP-PCR strategy to study mycobacterium tuberculosis gene expression during intracellular infection of macrophages [PhD]. Birmingham: University of Birmingham; 1998.

20. Cole ST, Brosch R, Parkhill J, Garnier T, Churcher C, Harris D, et al. Deciphering the biology of Mycobacterium tuberculosis from the complete genome sequence. Nature 1998;393(6685):537-44.

21. Garnier T, Eiglmeier K, Camus JC, Medina $\mathrm{N}$, Mansoor $\mathrm{H}$, Pryor $\mathrm{M}$, et al. The complete genome sequence of Mycobacterium bovis. Proc Natl Acad Sci U S A 2003;100(13):7877-82.

22. Carver TJ, Rutherford KM, Berriman $M$, Rajandream MA, Barrell BG, Parkhill J. ACT: the Artemis Comparison Tool. Bioinformatics 2005;21(16):3422-3.

23. van Helden $\mathrm{P}$, Victor $\mathrm{T}$, Warren $\mathrm{R}$, van Helden E. Isolation of DNA from Mycobacterium tuberculosis. In: Parish $\mathrm{T}$, Stoker N, editors. Mycobacterium tuberculosis Protocols. Totowa, New Jersey: Humana Press; 2001. p. 19-30.

24. Eisenach KD, Sifford MD, Cave MD, Bates JH, Crawford JT. Detection of Mycobacterium tuberculosis in sputum samples using a polymerase chain reaction. Am Rev Respir Dis 1991;144(5):1160-3.

25. Smith KC, Starke JR, Eisenach K, Ong LT, Denby M. Detection of Mycobacterium tuberculosis in clinical specimens from children using a polymerase chain reaction. Pediatrics 1996;97(2):155-60.

26. Gouveia AC, Eisenach KD, Vinhas SA, Ribeiro FK, Peres RL, Dietze R, et al. Use of in-house PCR for identification of Mycobacterium tuberculosis in BACTEC broth cultures of respiratory specimens. Mem Inst Oswaldo Cruz 2008;103(4):386-91.

27. Ojo D, Mafiana C, Adeniran-Sonola A. Prevalence of Mycobacterium tuberculosis and human immunodeficiency virus infections in Abeokuta, Ogun State, Nigeria. Nigerian Journal of Parasitology 2007;28(1):39-43.

28. Pennap G, Giyan J, Eleboda A. Prevalence of pulmonary tuberculosis (PTB) among people living with HIV/AIDS (PLWHA) in Keffi and its environs. Indian Journal of Microbiology 2009;49:233-236.

29. Ellner JJ, Goldberger MJ, Parenti DM. Mycobacterium avium infection and AIDS: a therapeutic dilemma in rapid evolution. J Infect Dis 1991;163(6):1326-35.
30. Cave MD, Eisenach KD, McDermott PF, Bates JH, Crawford JT. IS6110: conservation of sequence in Mycvobacterium tuberculosis complex and its utilization in DNA fingerprinting. Molecular and Cellular Probes 1991;5:73-80.

31. Idigbe EO, Anyiwo CE, Onwujekwe DI. Human pulmonary infections with bovine and atypical mycobacteria in Lagos, Nigeria. Journal of Tropical Medicine and Hygiene 1986;89:143-148.

32. Cadmus S, Palmer S, Okker M, Dale J, Gover $\mathrm{K}$, Smith $\mathrm{N}$, et al. Molecular analysis of human and bovine tubercle bacilli from a local setting in Nigeria. J Clin Microbiol 2006;44(1):29-34.

33. Nwobu G, Okodua M, Tatfeng Y. Comparative Study of HIV Associated Pulmonary Tuberculosis in Chest Clinics from Two Regions of Edo State, Nigeria. Online Journal of Health and Allied Sciences 2004;3(4).

34. Idigbe EO, Nasidi A, Anyiwo CE, Onubogu C, Alabi S, Okoye R, et al. Prevalence of Human Immunodeficiency Virus (HIV) Antibodies in Tuberculosis in Lagos, Nigeria. Journal of Tropical Medicine and Hygiene 1994;97(2):91-97.

35. Onipede AO, Idigbe O, A.K. A-N, Omojola $\mathrm{O}$, Oyelese AO, Aboderin AO, et al. Sero-prevalence of HIV antibodies in tuberculosis patients in Ile-Ife, Nigeria. East African Medical Journal 1999;76(3):127132.

36. Odaibo G, Gboun M, Ekanem E, Gwarzo S, Saliu I, Egbewunmi S, et al. HIV infection among patients with pulmonary tuberculosis in Nigeria. African journal of medicine and medical sciences. 2006;35(4):475-478.

37. Hopewell P, Jasmer R. Overview of Clinical Tuberculosis. In: Cole ST, Eisenach KD, McMurray DN, Jacobs WR, Jr., editors. Tuberculosis and the Tubercle Bacillus. First ed. Washington DC: ASM; 2005. p. 17-31.

38. Dance D. Ecology of Burkholderia pseudomallei and the interactions between environmental Burkholderia spp. and human-animal hosts. Acta Tropical 2000;74:159-168. 
